\title{
A gene replacement strategy for engineering nisin
}

\author{
Helen M. Dodd, ${ }^{1}$ Nikki Horn, ${ }^{1}$ Catriona J. Giffard ${ }^{2}$ and Michael J. Gasson ${ }^{1}$
}

Author for correspondence: Helen M. Dodd. Tel: +44 1603 255243. Fax: +44 1603507723. e-mail: DODDH@BBSRC.AC.UK

1 Department of Genetics and Microbiology, Institute of Food Research, Norwich Research Park, Colney, Norwich NR4 7UA, UK

2 Department of Biology, University of York, York, YO1 5DD, UK

\begin{abstract}
A lactococcal expression system was developed which allows the exclusive production of novel nisins encoded by mutated pre-nisin (nisA) genes. This system is based on a combination of a specifically constructed host strain and vectors which facilitate the genetic manipulation of the nisA gene. The wildtype chromosomal gene is effectively replaced with a variant nisA gene, by the technique of gene replacement. The recovery of full nisin immunity was employed as a means of directly selecting strains that had acquired an intact nisA gene by the gene replacement process. With this approach the other genes required for pre-nisin maturation are not affected and any alterations to DNA sequences are restricted to only those specific mutations introduced in the nisA gene. The effectiveness of the system was demonstrated by the expression of a number of variant nisA genes leading to the successful production and characterization of nisins containing the substitutions Dha5A, Dha33A, Dha5,33A, H27K, I3OW and K12L. The enhanced yields of these engineered nisin molecules, when compared to their production in a plasmidcomplementation system, underlines the improvement offered by this gene replacement strategy.
\end{abstract}

Keywords: nisin, protein engineering, gene replacement, antimicrobial peptide, Lactococcus lactis

\section{INTRODUCTION}

The lantibiotic nisin, produced by Lactococcus lactis, exhibits antimicrobial activity against a wide range of Gram-positive bacteria. Its ability to inhibit the growth of spoilage bacteria and food pathogens has resulted in the extensive use of nisin as a natural preservative in certain food products. With the advances made in the genetic analysis of nisin biosynthesis it has become possible to develop protein engineering strategies aimed at altering the biological properties of nisin (Dodd \& Gasson, 1994; Rauch et al., 1994). Studies of this type lead the way to an investigation of the structure-function relationships of this complex molecule. Furthermore, protein engineering may result in the construction of nisin variants that display altered biological activities or other advantageous properties extending its use as a broad-spectrum antimicrobial agent.

The nature of lantibiotic biosynthesis requires that expression systems for protein engineering must encode all the necessary maturation machinery for these post-

Abbreviations: Dha, Dehydroalanine; Dhb Dehydrobutyrine. translationally modified and secreted antimicrobial peptides. For nisin biosynthesis it has been established that, in addition to the structural gene nis $A$, at least ten additional genes are involved in production of the mature molecule (Kuipers et al., 1993; Engelke et al., 1994; Siegers \& Entian, 1995). Nisin-producing strains, carrying plasmidencoded variant nis $A$ genes, have been employed for the production of engineered nisins, in addition to the wildtype nisin expressed by the resident gene (Kuipers et al., 1992). We have previously described the development of a $\mathrm{Nis}^{-}$lactococcal expression system in which the nis $A$ gene of the host, FI7332, was insertionally inactivated (Dodd et al., 1992). This deficiency can be complemented by provision of a plasmid-encoded nis $A$ gene which has been subjected to site-specific mutagenesis. With this approach, only the product of the variant nis $A$ gene is subject to the processing specified by the other Nis proteins. Hence, this strategy has the advantage of ensuring the exclusive expression of a variant pre-nisin and furthermore allowed an instant assessment to be made of the activity of the mature modified peptide (Dodd $e t$ al., 1992). The construction of a similar lactococcal strain has been described which contains an inactivated nis $A$ gene (Kuipers et al., 1993). The expression of plasmid-encoded 
nis $A$ and nis $Z$ genes in this host has resulted in the successful production of nisin and nisin variants.

Here, we describe the development of an alternative lactococcal expression system in which the technique of gene replacement was used to incorporate a copy of the $n i s A$ gene into a nis $A$-deficient nisin operon. Vectors have been constructed that facilitate the genetic manipulation of the nis $A$ gene and enable these variant genes to be substituted for the chromosomal wild-type gene. To illustrate the use of this protein engineering strategy, the construction of a number of strains encoding variant nis $A$ genes is described. A range of nisin variants have been produced with the aim of furthering investigations into the structure-function relationships and mode of action of this complex molecule. The expression and production of these engineered nisins, as compared to that achieved in the previously reported plasmid-complementation system (Dodd et al., 1992, 1995), is discussed.

\section{METHODS}

Microbiological techniques and strains used. The lactococcal strains used in this study and their derivation are given in Table 1. Unless stated otherwise, cultures were grown at $30^{\circ} \mathrm{C}$ in $\mathrm{M} 17$ medium (Terzaghi \& Sandine, 1975) supplemented with $0.5 \%$ (w/v) glucose (GM17 medium). Screening strains for resistance to antibiotics was carried out at the following levels: erythromycin, $\left(\mathrm{Em}^{\mathrm{r}}\right) 5 \mu \mathrm{g} \mathrm{ml}^{-1}$; streptomycin, $\left(\mathrm{Sm}^{\mathrm{r}}\right) 200 \mu \mathrm{g} \mathrm{ml}^{-1}$.

Escherichia coli MC1022 (Casadaban \& Cohen, 1980) was the host strain for construction and molecular analysis of recombinant plasmids derived from the vectors pMTL23p (Chambers et al., 1988), pGEM-3Z (Promega), pCR II (Invitrogen) and $\mathrm{pG}^{+}$host6 (Appligene). Recombinant plasmids used, and constructed during the course of this study, are shown in Fig. 1. E. coli cultures were propagated at $37^{\circ} \mathrm{C}$ in $\mathrm{L}$ broth (Lennox, 1955). Selection for ampicillin resistance $\left(\mathrm{Ap}^{\mathrm{r}}\right)$ was with $200 \mu \mathrm{g}$ ampicillin $\mathrm{ml}^{-1}$ and selection for erythromycin resistance $\left(\mathrm{Em}^{\mathrm{r}}\right)$ was with $400 \mu \mathrm{g}$ erythromycin $\mathrm{ml}^{-1}$.

The production of active nisin by lactococcal strains was assayed by both deferred and direct means. Plate diffusion bioassays were performed as previously described (Dodd et al., 1992). Colonies growing on the surface of a GM17 plate were directly assayed by inverting over chloroform for $12 \mathrm{~min}$ and overlaying with agar seeded with the nisin-sensitive $L$. lactis strain MG1614. Plates were incubated overnight and zone sizes around colonies were compared with those of controls. Nisin immunity was determined by streaking cultures on a series of GM17 agar plates containing an increasing concentration of nisin and assessing the degree of growth at the different nisin levels. Control cultures FI5876 (positive) and MG1614 (negative) were included on each plate. Nisin $\left(50000 \mathrm{U} \mathrm{mg}^{-1}\right)$ was kindly provided by Aplin \& Barrett.

MICs were determined by assaying for growth inhibition in microtitre plates. Overnight cultures of sensitive indicator organisms were diluted to 1 in 100 either in GM17 broth for $L$. lactis MG1614 or in BHI broth for Micrococcus luteus NCIMB 8166 and $100 \mu \mathrm{l}$ was added to each well. A dilution series of purified nisin and nisin variants (in duplicate) was added to the cell suspensions over a range of concentrations appropriate for detecting inhibition of growth. Plates were incubated at $30^{\circ} \mathrm{C}$ for $8 \mathrm{~h}$ (with shaking for $M$. luteus) and $\mathrm{OD}_{630}$ readings (Titertek multiskan NCC plate reader) were taken hourly. During this time growth of the indicator strain, in the absence of nisin, reached a maximum cell density and at this point the MIC value was taken as the lowest concentration of nisin, or nisin variant, which inhibited growth.

Molecular techniques. Plasmid DNA isolation was carried out as described by Dodd et al. (1990) and Horn et al. (1991). Restriction enzymes and other DNA-modifying enzymes from various sources were used according to the suppliers recommendations. Recombinant plasmids were recovered by transformation of E. coli as described previously by Dodd et al. (1992) or by electroporation of $L$. lactis according to the method of

Table 1. L. lactis strains used in this study

\begin{tabular}{|c|c|c|c|c|}
\hline Strain & $\begin{array}{l}\text { nis } A \text { gene/ } \\
\text { mutation* }\end{array}$ & $\begin{array}{c}\text { Active } \\
\text { product } \dagger\end{array}$ & $\begin{array}{c}\text { Immunity } \\
(\%) \S\end{array}$ & Reference/source \\
\hline MG1614 & - & - & $0 \cdot 04$ & Gasson (1983) \\
\hline F15876 & nis $A$ (wild-type) & + & 100 & $\begin{array}{l}\text { Dodd et al. (1990); } \\
\text { Horn et al. (1991) }\end{array}$ \\
\hline F17990 & $\Delta n i s A$ & - & 5 & This work \\
\hline F17898 & $n i s A$ & + & 100 & This work \\
\hline F18003 & $n i s A$ & - & 5 & This work \\
\hline $\mathrm{F} 18070$ & $n i s A / \mathrm{S} 5 \mathrm{~A}$ & + & 100 & This work \\
\hline F18198 & $\operatorname{nis} A / \mathrm{S} 33 \mathrm{~A}$ & + & 100 & This work \\
\hline F18199 & nis $A / \mathrm{S} 5 \mathrm{~A}, \mathrm{~S} 33 \mathrm{~A}$ & + & 100 & This work \\
\hline $\mathrm{F} 18290$ & nis $A / \Delta \mathrm{M} 21$ & - & 20 & This work \\
\hline F18289 & nis $A / \mathrm{I} 30 \mathrm{~W}$ & + & 10 & This work \\
\hline F18256 & nis $A / \mathrm{K} 12 \mathrm{~L}$ & + & 20 & This work \\
\hline F18307 & nis $A / \mathrm{H} 27 \mathrm{~K}$ & + & 100 & This work \\
\hline
\end{tabular}

* The site-specific mutations in the nis $A$ gene are denoted according to the nomenclature proposed by de Vos et al. (1991).

† Determined from cell-free supernatants in plate diffusion bioassays.

\Level of immunity to nisin is given relative to that of the wild-type Nis ${ }^{+}$strain FI5876 $\left(50 \mu \mathrm{g} \mathrm{ml}^{-1}\right)$. 


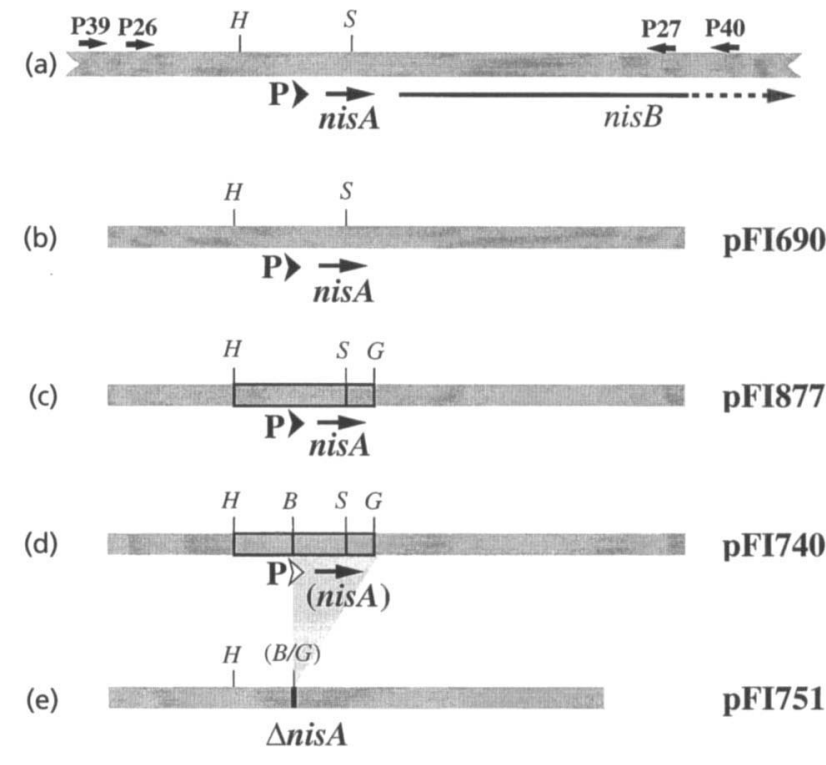

Fig. 1. Gene-replacement vector construction. (a) Region of FI5876 chromosome encoding nisA and start of nis $B$ gene. (b)-(e) PG'host6-derivatives containing cloned FI5876 sequences. The nisin promoter is indicated under the maps by solid arrowheads labelled $P$ and the equivalent disrupted sequences are indicated by an open arrowhead. Relevant restriction enzyme sites: $B, B a m H I ; G, B g / l l ; H$, Hincll; $S$, Sacl. The shaded area between (d) and (e) indicates the region of pFI740 that is deleted in pFI751. The chromosomal location of primers P39, P26, P27 and P40 are shown in (a). The nisA cassette, into which specific mutations can be incorporated, is boxed.

Holo \& Nes (1989) with the modifications of Dodd et al. (1992). Conditions used for PCR were as described in Horn et al. (1991) and primers were synthesized on an Applied Biosystems DNA synthesizer (model 381A). Fragments generated for the construction of gene-replacement vectors were amplified using Dynazyme (Flowgen) and cloned into PCR II prior to nucleotide sequence confirmation. For routine PCR screening of recombinant clones AmpliTaq DNA polymerase (Perkin Elmer) was used. Direct nucleotide sequence determination of purified PCR-generated templates was carried out on an Applied Biosystems DNA Sequencer (model 373A) using the manufacturer's Taq DyeDeoxy Terminator Cycle sequencing kit.

Construction of nisA gene-replacement vectors. The thermosensitive shuttle vector $\mathrm{pG}^{+}$host 6 was employed for gene replacement. Homologous plasmid DNA originated from pFI172 (Dodd et al., 1990) which contains a $2.1 \mathrm{~kb}$ region of the FI5876 chromosome (Fig. 1a) including the nis $A$ gene. The entire fragment was subcloned into $\mathrm{pG}^{+}$host 6 to generate the nis $A$ gene-replacement vector pFI690 (Fig. 1b). Subsequent manipulation of this region, resulting in inactivation or mutagenesis of the nis $A$ gene (see below), was carried out in either vector pGEM-3Z or pMTL23P. The final step in the construction of each gene-replacement vector was cloning the modified $2.1 \mathrm{~kb}$ fragment into $\mathrm{pG}^{+}$host 6 .

Construction of pFI751, $\Delta$ nisA gene-replacement vector. Inactivation of the nis $A$ gene was achieved by deletion of the entire coding region. In order to confine the deletion to just $n i s A$ it was necessary to engineer additional restriction enzyme sites on either side of the gene. Primers P13 (5'-
AACGGATCCGATTAAATTCTGAAGTTTG) and P32 (5'CCATGTCAGATCTAACAAAATAC) were designed, for PCR amplification of this region of the chromosome, that incorporated respectively a Bam HI site $80 \mathrm{bp}$ upstream of the start of nis $A$ and a $B g / \mathrm{II}$ site 25 bp beyond the stop codon (Fig. 2). Primers P26 (5'-ATAGTTGACGAATATTTAATAATTTT) and P25 (5'-AATCGGATCCGTTTATTATGCTCGC) were employed for amplification of the upstream $211 \mathrm{bp} H i n \mathrm{cII} /$ Bam HI fragment and primers P28 (5'-GTTAGATC'TGACATGGATAC) and P27 (5'CTTGGTCGACACCATATTTT) were employed for the downstream $1.1 \mathrm{~kb} B g / \mathrm{II} / \mathrm{Sal}$ fragment (relevant restriction enzyme sites are underlined). The template used for these PCRs was pFI172 DNA. The resulting plasmid, pFI740 (Fig. 1d), contained an intact nis $A$ gene flanked by engineered $B a m \mathrm{HI}$ and $B g / \mathrm{II}$ sites, all contained within $2 \cdot 1 \mathrm{~kb}$ of sequences homologous to the chromosome. Digestion of $\mathrm{pFI740} \mathrm{with} \mathrm{these} \mathrm{two}$ enzymes, followed by ligation of their compatible ends, resulted in the generation of plasmid pFI751 (Fig. 1e) in which the nis $A$ gene has been deleted (designated $\Delta$ nis $A$ ). PCR amplification of this part of the plasmid and nucleotide sequence analysis of the region spanning the deletion in the amplified fragment confirmed that fusion of the BamHI and BglII sites had occurred.

Construction of nisA site-specific mutations. The construction of the plasmid pFI877 (Fig. 1c) allowed a cassette mutagenesis strategy to be employed for the introduction of site-specific mutations into the nis $A$ gene. This pGEM-3Z-derivative contains the equivalent sequences to those in pFI690 (Fig. 1b), but includes the engineered $B g / \mathrm{II}$ site downstream of nis $A$ in pFI740 (Figs 1d, 2). In pFI877 a Hincll/SacI fragment encoding the amino-terminal region of nis $A$ and upstream expression signals, replaced the PCR-generated fragment of pFI740 that contains the engineered Bam $\mathrm{HI}$ site. Thus, the only difference between sequences in pFI877 and the equivalent chromosomal wild-type sequences is the presence of an additional $B g /$ II site downstream of the nis $A$ gene. Primers were designed for PCRmediated mutagenesis of the nis $A$ cassette (Fig. 2). The amplified cassette fragments, containing a specific mutation, were then substituted for the wild-type fragment of $\mathrm{pFI877.} \mathrm{The} \mathrm{mutations}$ nis $A / \mathrm{S} 5 \mathrm{~A}$ and nis $A / \mathrm{K} 12 \mathrm{~L}$ were incorporated in primers P17 (5'-TCAGAGCTCCTG'T'T'TACAACCGGGTGTACATAGTGCAAT) and PCJ1 (5'-TCAGAGCTCCTGTTAGACAAC), respectively (the sites of mutation are underlined). These primers, in conjunction with P26, were used to amplify the HincII/SacI cassette fragment. Primer PCJ5 (5'-CAGGAGCTCTGGG'T'TGAACA) together with primer P32 generated a $\mathrm{SacI} / \mathrm{Bg} / \mathrm{II}$ fragment containing the deletion mutation nis $A / \Delta \mathrm{M} 21$. Other mutations required the technique of spliced-overlap extension with the specific mutations being incorporated on two complementary primers which span the mutation site (Dodd et al., 1992). The mutations in nis A/S33A involved the primers P18 (5'-TAGTATTCACGTAGCTAAATAACC) and P19 (5'-TTGGT'TATTTAGCTACGTGAATAC); nis $A / \mathrm{I} 30 \mathrm{~W}$ involved primers PCJ6 (5'-CATTGTAGTTGGCACGTAAGC) and PCJ7 (5'-GCTTACGTGCCAACTACAATG) and nis $A / \mathrm{H} 27 \mathrm{~K}$ involved primers P58 (5'-CTTGTAAATGTAGTATTCACGTAAG) and P59 (5'-CTTACGTGAATACTACATTTACAAG). These mutations were contained within the $S a c I / B g / I I$ fragment defined by primers P10 (5'-CAGGAGCTCTGATGGGTTG) and P32 (Fig. 2). The PCR-generated fragments were cloned into the gene-replacement vector to create an uninterrupted coding region specifying the variant nis $A$ gene. In the case of nis $A / \mathrm{S} 5 \mathrm{~A}, \mathrm{~S} 33 \mathrm{~A}$ both cassette fragments contained a mutation (Fig. 2). After gene replacement, PCR analysis using P39 (5'-GACTTTCCATTATGCTTGGATTTT'T) and P40 (5'-GCTCCTATG- 


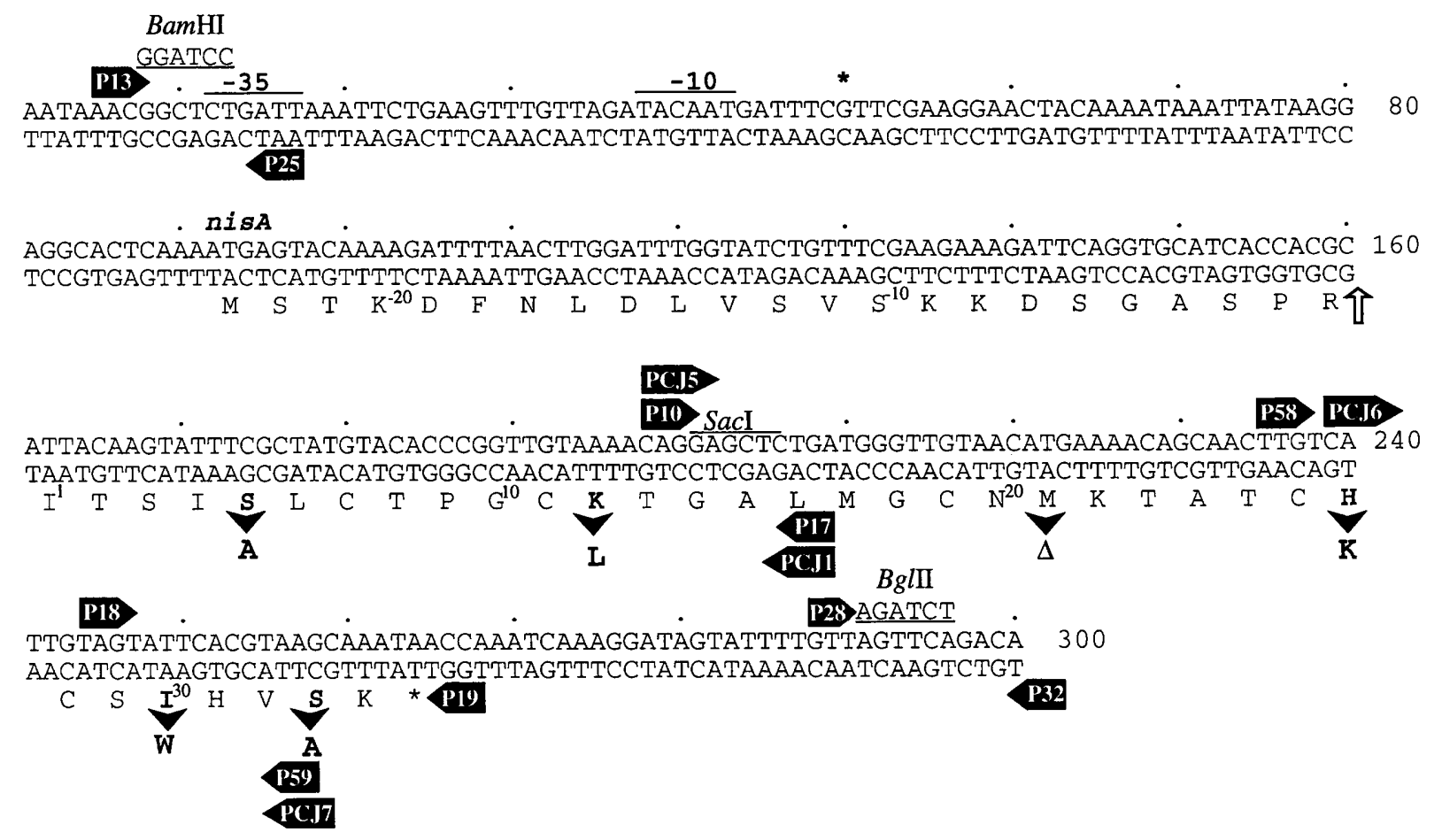

Fig. 2. Double-stranded nucleotide sequence of nis $A$ gene and pre-nisin amino acid sequence. The -35 and -10 regions and the transcription initiation site are indicated together with restriction enzyme sites used in the nis $A$ gene cassette (see Fig. 1) above the DNA sequence. The location of primers ( 5 '-end) employed in amplification of the cassette fragments and PCR-mediated mutagenesis are shown, above and below the sequence, as horizontal black arrows indicating the direction of DNA synthesis. Specific amino acid substitutions, as a result of the mutagenesis, are shown below the pre-nisin sequence.

CCAAATGTAGAATC; Fig. 1a) and nucleotide sequence determination confirmed the correct incorporation of mutations in the chromosome.

Gene replacement protocol. L. lactis FI7990 transformants containing derivatives of $\mathrm{pG}^{+}$host 6 were established at $28^{\circ} \mathrm{C}$ and grown overnight at this temperature in GM17 containing $5 \mu \mathrm{g} \mathrm{Em} \mathrm{ml^{-1 }}$ (GM17-Em). Approximately $10^{5}$ cells were used to inoculate $100 \mathrm{ml}$ fresh, pre-warmed GM17-Em and the cultures were incubated at $28{ }^{\circ} \mathrm{C}$ for $4 \mathrm{~h}$. Incubation was continued overnight at the elevated temperature of $37^{\circ} \mathrm{C}$. This temperature is non-permissive for $\mathrm{pG}^{+}$host 6 replication (Biswas et al., 1993), and the presence of Em in the growth medium ensures selection for those cell lines in which a single crossover results in the integration of the derivative in the chromosome at the site of plasmid/chromosome homology (Leenhouts et al., 1989, 1990; Chopin et al., 1989). Pre-warmed GM17 (with no Em) was inoculated with approximately $10^{5}$ cells from the overnight culture and incubated overnight at $28^{\circ} \mathrm{C}$. At this temperature, plasmid replication is possible and recombination between homologous sequences flanking the integrated plasmid results in its excision from the chromosome. Depending on where the second crossover occurs, either sequences originating from the integrated plasmid or the original sequences will be retained in the chromosome. Cultures were diluted and spread, to obtain single colonies, on GM17 agar plates. In order to cure the cells of plasmid, the plates were incubated at $37^{\circ} \mathrm{C}$. Colonies (approximately 50) were screened for loss of the $\mathrm{pG}^{+}$host6derivative by patching onto GM17-Em plates. When using this technique to disrupt the nis $A$ gene, colonies were also screened for loss of nisin activity and PCR analysis of the relevant region of the chromosome was used to confirm any changes at the molecular level.

Purification of engineered nisins. Nisin variants were purified from 11 of culture supernatants of producing strains by hydrophobic-interaction chromatography (Mulders et al., 1991) on a TSK Toyopearl Butyl $650 \mathrm{M}$ column $(5 \times 20 \mathrm{~cm})$. Active fractions were lyophilized and further purified on a Waters $\mu$ Bondapak C18 reverse-phase semi-prep HPLC column $(15 \mathrm{~cm} \times 19 \mathrm{~mm})$. The elution profile involved a linear gradient $25-50 \%$ buffer B ( $8 \mathrm{mM}$ trifluoroacetic acid in $90 \%, \mathrm{v} / \mathrm{v}$, aqueous acetonitrile) in buffer $\mathrm{A}(10 \mathrm{mM}$ trifluoroacetic acid in $10 \%, \mathrm{v} / \mathrm{v}$, aqueous acetonitrile) over $40 \mathrm{~min}$ at $2.0 \mathrm{ml} \mathrm{min}$. The eluent was monitored at $195-300 \mathrm{~nm}$ using a scanning UV detector. The concentrations of nisin variants was confirmed by analytical HPLC with the area under the peak relating to the amount of nisin injected. Calibration curves were determined by injecting known concentrations of pure nisin variants.

\section{RESULTS}

\section{Inactivation of chromosomally encoded FI5876 nisA gene}

The generation of a lactococcal host suitable for the production of engineered nisins involved adaptation of the well-characterized nisin-producing strain $L$. lactis FI5876 (Dodd et al., 1990; Horn et al., 1991). In order to develop a gene replacement system for variant nisin expression it was necessary to first construct a $\mathrm{Nis}^{-}$ 


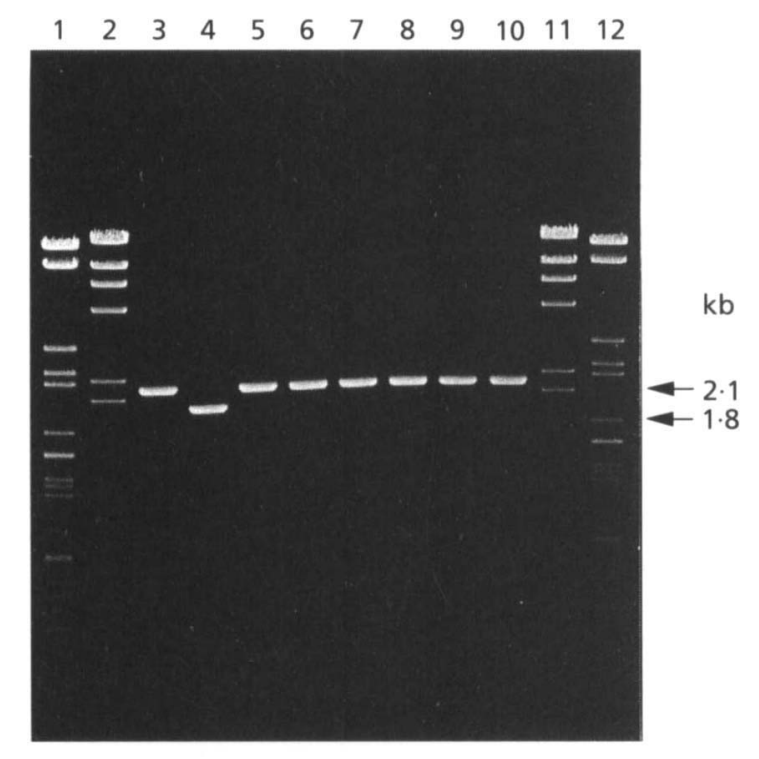

Fig. 3. Agarose gel electrophoresis of $P C R$ fragments generated with primers P39 and P40. PCR reactions were carried out on colonies of: tracks: 3, FI5876; 4, FI7990; 5-10, Fl7990/pG+host6derivatives after the gene replacement procedure. Size standards: tracks 1 and 12, $\lambda$ DNA digested with Bgll; tracks 2 and $11, \lambda$ DNA digested with HindIII.

derivative by inactivating the resident nis $A$ gene of FI5876. Plasmid pFI751 (Fig. 1e) was constructed for this purpose and using gene replacement an approximately $300 \mathrm{bp}$ deletion (designated $\Delta n i s A$, Fig. 2) was incorporated in the chromosome, in place of the nis $A$ gene. $\mathrm{Nis}^{-}$strains, recovered at a frequency of about $10 \%$, could be readily distinguished from the parent strain by PCR analysis. Primers P39 and P40 were designed from sequences located outside the region cloned into the genereplacement vectors (Fig. 1a). Using these primers, a $1.8 \mathrm{~kb}$ fragment was amplified in the $\Delta$ nis $A$ containing strains (Fig. 3, track 4) compared to a $2.1 \mathrm{~kb}$ fragment generated from the equivalent region of FI5876, encoding wild-type nis $A$ (Fig. 3, track 3). In one of the $\mathrm{Nis}^{-}$strains, designated FI7990, nucleotide sequence analysis of the PCR-generated $1.8 \mathrm{~kb}$ fragment confirmed that $\Delta$ is $A$ was incorporated in the correct region of the chromosome. The potential of FI7990 as an expression host for variant nisins was demonstrated by reverting the $\Delta$ nis $A$ mutation to wild-type, in equivalent gene replacement experiments, using the vector pFI690 (Fig. 1b). The recovery of nisin production, by strain FI7898 (Table 1), indicated that the $\mathrm{Nis}^{-}$phenotype exhibited by FI7990 was due solely to the deletion that was previously introduced and that the other nisin-biosynthesisdeterminants were unaffected by the gene replacement process. PCR analysis of the $\mathrm{Nis}^{+}$colonies demonstrated that the $\Delta$ nis $A$ mutation ( $1.8 \mathrm{~kb}$ fragment) had been replaced by the wild-type nis $A$ gene $(2 \cdot 1 \mathrm{~kb}$ fragment). The use of PCR to readily identify strains at the molecular level that have undergone gene replacement (see Fig. 3) is a particular advantage of FI7990 as a host strain for engineering nisin.

\section{Use of nisin immunity to select gene replacement strains expressing variant $n$ is $A$ genes}

The gene replacement experiments, carried out in the construction and testing of FI7990, indicated that substitution of chromosomal sequences for the equivalent homologous region carried by the $\mathrm{pG}^{+}$host 6 -derivative, occurred at a very low frequency $(<1 \%$ recovery of colonies exhibiting nisin activity). The restoration of a $\mathrm{Nis}^{+}$phenotype necessitates a functional nisin immunity mechanism and this requires the expression of nis $A$ and other genes in the nisin operon, under the control of the nisin promoter. With this in mind, the gene replacement protocol that was employed for the construction of FI7990 was modified to facilitate the identification of derivatives that had acquired nis $A$ or variant nis $A$ genes that resulted in nisin production. The recovery of $\mathrm{Nis}^{+}$colonies hinged on the fact that these cells must necessarily also be immune to nisin at the level at which they were producing this antimicrobial peptide. In the modified gene replacement protocol the final step included the addition of nisin (to $10 \mu \mathrm{g} \mathrm{ml}^{-1}$ ) to the GM17 agar plates. Colonies that were immune to this level of nisin were screened for $\mathrm{Em}^{\mathrm{r}}$ and assayed for nisin production. PCR analysis was also used to determine the organization of genomic sequences. Fig. 3 shows the fragments generated by PCR (using primers P39 and P40, Fig. 1a) from six colonies that had been through the gene replacement procedure. All were found to have acquired a functional copy of a nis $A$ gene (in this case nis $A / \mathrm{S} 5 \mathrm{~A}$ ) as shown by the $300 \mathrm{bp}$ increase in size of the PCR fragment. This procedure was found to be a very reliable means of identifying $\mathrm{Nis}^{+}$derivatives of FI7990, and the majority of colonies (approximately $90 \%$ ) screened in this way had undergone gene replacement and were expressing a functional nis $A$ gene or variant in place of the chromosomal lesion, $\triangle$ nis $A$.

The effect of disruption of the nis $A$ gene on immunity of the host strain to nisin has been described previously (Dodd et al., 1992; Kuipers et al., 1993) and, as would be expected, FI7990 ( $\Delta$ nis $A$ ) displayed reduced immunity. The construction of this strain involved primer 13 (Fig. 2) which was designed such that most of the proposed promoter region (Kuipers et al., 1993) was deleted (Fig. 1). The absence of these nisin expression signals resulted in FI7990 displaying significantly more sensitivity to nisin than strains that were $\mathrm{Nis}^{-}$as a result of insertion or frameshift mutations within the nis $A$ gene. (Dodd et al., 1992). Sensitivity was evident at nisin concentrations above $5 \mu \mathrm{g} \mathrm{ml}^{-1}$ compared to the wild-type strain which will continue growing in the presence of more than $50 \mu \mathrm{g}$ nisin $\mathrm{ml}^{-1}$ (Table 1). Nis ${ }^{-}$strains that retained the upstream promoter sequences were immune to intermediate levels of nisin, the actual level being influenced by induction with nisin (H. M. Dodd, W. C. Chan, N. Horn \& M. J. Gasson, unpublished data). The fact that FI7990 was sensitive to the levels of nisin employed in the selection plates $\left(10 \mu \mathrm{g} \mathrm{ml}^{-1}\right)$ was crucial for the gene replacement procedure described above and ensured that it was possible to discriminate between the parent strain and derivatives that were producing an active nisin variant. 
Table 2. MICs of engineered nisins

\begin{tabular}{|lcc|}
\hline Nisin A variant & \multicolumn{2}{c|}{ MIC $\left(\boldsymbol{\mu g ~ \mathbf { ~ m l } ^ { - 1 } )}\right.$} \\
\cline { 2 - 3 } & $\begin{array}{r}\text { L. lactis } \\
\text { MG1614 }\end{array}$ & $\begin{array}{c}\text { Micrococcus luteus } \\
\text { NCFIB8166 }\end{array}$ \\
\hline A (wild-type) & $0 \cdot 13$ & $0 \cdot 25$ \\
Dha5A & $0 \cdot 25$ & $0 \cdot 25$ \\
Dha33A & $0 \cdot 25$ & $0 \cdot 25$ \\
Dha5A/Dha33A & $1 \cdot 00$ & $0 \cdot 50$ \\
H27K & $0 \cdot 13$ & $0 \cdot 25$ \\
K12L & $0 \cdot 13$ & $0 \cdot 25$ \\
I30W & $0 \cdot 16$ & $0 \cdot 33$ \\
\hline
\end{tabular}

The low-level immunity to nisin was also displayed by the FI7990-derivative FI8003 (Table 1), in which the plasmid pFI740-encoded nis $A$ (Fig. 1d) was incorporated in the chromosome in place of $\Delta$ nis $A$. This strain had a $\mathrm{Nis}^{-}$ phenotype despite carrying an intact nis $A$ gene. This result contrasts with that of an equivalent gene replacement experiment, with plasmid pFI690 (Fig. 1b), which generated the $\mathrm{Nis}^{+}$strain FI7898 (Table 1). The only difference between the two sequences involved is that FI8003 has an additional Bam HI site incorporated $80 \mathrm{bp}$ upstream of the ATG start codon of nis $A$, and a $B g / I I$ site immediately downstream of the coding region. The BamHI site overlaps with the proposed -35 region of the promoter identified by Kuipers et al. (1993) and the single base pair change introduced as a result of engineering this restriction site has the effect of converting the -35 sequence from CTGATT to CCGATT (Fig. 2).

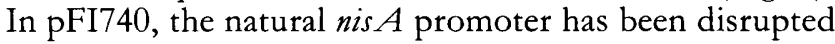
and hence FI8003, which has incorporated the BamHI site by gene replacement, has acquired the defective promoter.

\section{Production of engineered nisins}

The gene replacement strategy was successfully employed to select for several derivatives of FI7990 that are now exclusively producing engineered nisins in place of wildtype nisin. Strain FI8290, encoding the variant gene nis $A / \Delta \mathrm{M} 21$, did not produce detectable levels of an active peptide. However, strains encoding the other mutated nis $A$ genes in this study all generated a biologically active product (Table 1) which was purified to homogeneity allowing further characterization. Verification of the predicted changes to the nisin molecules was provided by electrospray mass spectrophotometry (C. J. Giffard \& A. Parr, unpublished data). 2-D NMR spectra of the engineered peptides Dha5A nisin A, Dha33A nisin A and Dha5A/Dha33A nisin A (W. C. Chan, B. W. Bycroft \& G. C. K. Roberts, unpublished data) provided further structural verification and confirmed the lack of Dha residues in these molecules.

The activity of the engineered nisins, relative to wild-type nisin, was determined by calculating the MICs of the purified peptides. The results (Table 2) indicate that the
Dha residues, in both the functionally important ring A (Chan et al., 1989) and in position 33, are not critical for activity. However, the variant containing both mutations displays a significantly lower activity than nisin A (approximately tenfold lower against $L$. lactis and twofold lower against $M$. luteus). $\mathrm{H} 27 \mathrm{~K}$ nisin $\mathrm{A}$ and $\mathrm{K} 12 \mathrm{~L}$ nisin A displayed the same MIC values as nisin A, indicating that these mutations had not affected the specific activity. The substitution of isoleucine for a tryptophan residue at position 30 was found to slightly diminish antimicrobial activity (Table 2). Despite displaying a negligible decrease in activity, the yield of both $\mathrm{I} 30 \mathrm{~W}$ nisin $\mathrm{A}$ and $\mathrm{K} 12 \mathrm{~L}$ nisin A (in cell-free extracts) was significantly lower, approximately 1 and $10 \%$, respectively, than that of wild-type levels. A parallel reduction in the immunity levels was also evident for strains expressing these variant nis $A$ genes. All the other FI7990-derivatives were immune to wild-type levels of nisin (Table 1).

\section{DISCUSSION}

A lactococcal expression system for engineering nisin has been developed which employs the technique of gene replacement. This system, as with the FI7332 plasmidcomplementation approach (Dodd et al., 1992), achieves exclusive production of the engineered nisin. However, the genomes of engineered strains, generated by gene replacement, differ from wild-type only in the presence of the directed mutation and this minimal change has potential advantages over the former system for regulation and practical uses. As nisin biosynthesis is an autoinducible mechanism (Kuipers et al., 1995), the overall level of expression of the mature peptide is likely to be influenced by the effectiveness of that particular nisin variant as an inducing agent. Nevertheless, an advantage of the gene replacement approach is that by maintaining normal gene dosages the relative levels of expression of the individual genes within the nisin operon are likely to remain constant resulting in the correct balance of gene products. Furthermore, as complementation is not employed to recover a Nis ${ }^{+}$phenotype, this system does not suffer from the need to maintain plasmid-encoded functions.

Gene replacement is a valuable technique for the functional analysis of the bacterial genome, including that of L. lactis (Leenhouts et al., 1989, 1990; Chopin et al., 1989). This approach has been used effectively in gene disruption experiments with Bacillus subtilis, investigating the role of spa genes involved in biosynthesis of the related lantibiotic subtilin (Klein et al., 1992; 1993; Klein \& Entian, 1994; Liu \& Hansen, 1992). In the course of the work with $L$. lactis reported in the present paper it became evident that the expected ratios of gene replacement products were not being achieved. The protocol used involves the integration of the thermosensitive plasmid, $\mathrm{pG}^{+}$host 6 in the chromosome, followed by its excision. Assuming that crossovers occur with equal frequency between homologous sequences on either side of the mutation, it would be predicted that, following $\mathrm{pG}^{+}$host 6 excision, the numbers of cells carrying the introduced mutation and 
those remaining identical to the parent strain would be the same. This did not prove to be the case and the majority of colonies screened retained the genetic organization of the parent strain FI7990. The reason for this is not clear, but it suggests that the immediate effect of integration of a functional nis $A$ gene is detrimental to the host cell. It has been reported that expression of the nis $A$ gene precedes that of the adjacent nis $B$ gene by $30 \mathrm{~min}$ (Engelke $e t$ al., 1994) and transcription of other determinants in the nisin gene cluster may be similarly delayed, with respect to prenisin production. Those strains that acquire a nis $A$ gene by gene replacement may not have recovered full immunity before the nisin molecule exerts its antimicrobial action and hence growth would be impeded.

The deletion of the nisin promoter in FI7990 (Fig. 1e) generates a $\mathrm{Nis}^{-}$strain that cannot be complemented by provision of plasmid-encoded nis $A$, and which displays significantly reduced levels of immunity. This observation was fundamental to the development of an effective gene replacement method in that it facilitates the identification of FI7990-derivatives that express engineered nisin variants. The modified protocol uses recovery of full nisin immunity as a means of directly selecting those $\mathrm{Nis}^{+}$ strains generated by gene replacement and relies on the fact that the parent strain will not grow on these selective plates. $\mathrm{Nis}^{-}$strains that retained the upstream promoter sequences (eg. by introduction of a frameshift mutation in nis $A$ ) were unsuitable as recipients for the gene replacement protocol. Whilst their immunity was also reduced, it was found that restoration of nisin immunity could be induced as a consequence of growing in the presence of $10 \mu \mathrm{g}$ nisin $\mathrm{ml}^{-1}$ in the selective medium $(\mathrm{H}$. M. Dodd \& W. C. Chan, unpublished data). Hence, these strains grew well at the levels of nisin that were found to be optimal for selection of $\mathrm{Nis}^{+}$recovery in FI7990. Primer-extension mapping of the nis $A$ gene transcript has identified the promoter and the transcription start point (Kuipers et al., 1993). Experiments carried out with strains generated in this study confirm that the region upstream of nis $A$ has promoter activity and underline the importance of the -35 region for expression of both nisin biosynthesis and immunity.

Protein engineering provides a powerful means of studying the structure-activity relationships of lantibiotics. The introduction of amino acid changes in nisin facilitates an investigation of the importance of specific residues and certain structural features of the peptide in its biological activity. The dehydro residues in nisin are a source of structural instability as shown by the production of spontaneous degradation products resulting from cleavage of the peptide bond at $\mathrm{Dha}_{5}$ and $\mathrm{Dha}_{33}$ (Chan et al., 1989). It has recently been reported that substitution of $\mathrm{Dha}_{5}$ for a dehydrobutyrine $\left(\mathrm{Dhb}_{5}\right)$ generates a molecule displaying greater resistance to acid degradation (Rollema et al., 1995). In addition, it has been proposed that equivalent Dha at position 5 in the related lantibiotic subtilin, is involved in the antimicrobial activity against outgrowth of bacterial spores (Liu \& Hansen, 1993). These modified residues are obvious targets for engineering the nisin molecule and the gene replacement strategy was initially employed to investigate their role in the biological properties of nisin. From analysis of the strains containing the variant genes nis $A / \mathrm{S} 5 \mathrm{~A}$, nis $A /$ $\mathrm{S} 33 \mathrm{~A}$ and nis $A / \mathrm{S} 5,33 \mathrm{~A}$, it was concluded that the modified hosts, encoding all the nisin biosynthesis machinery, could successfully be adapted to express the mutated genes. The resulting pre-nisins were then matured to generate functional engineered nisins demonstrating that Dha residues at positions 5 and 33 are not essential for antimicrobial activity. Further characterization of purified Dha5A nisin A has demonstrated that this nisin variant has lost the ability to inhibit the outgrowth of B. subtilis spores (W. C. Chan, K. McClean, B. W. Bycroft \& G. C. W. Roberts, personal communication). This is consistent with the proposal that the dehydro residues of lantibiotics play a role in an alternative mechanism of antimicrobial action directed against spore outgrowth (Liu \& Hansen, 1993).

Interest in developing alternative applications for nisin has prompted the construction of strains producing other variant molecules. $\mathrm{H} 27 \mathrm{~K}$ nisin $\mathrm{A}$ was generated with the intention of changing the biological properties of the wild-type molecule. The equivalent mutation in nisin $\mathrm{Z}$ has recently been shown to result in a significant increase in solubility compared to the wild-type molecule (Rollema et al., 1995). Other nisin variants have been specifically designed with the purpose of furthering investigations into the mode of action of nisin. With K12L nisin A, the effect of increasing the overall positive-charge of the molecule is being investigated in phospholipid bilayer studies. The introduction of a tryptophan residue in $\mathrm{I} 30 \mathrm{~W}$ nisin A allows a fluorescent marker to be incorporated into the molecule facilitating the analysis of interaction of nisin with the membrane surface.

Strains producing the three nisin variants containing Dha $\rightarrow$ Ala substitutions (Table 1 ) have been constructed using both the FI7332 plasmid-complementation system (Dodd et al., 1992, 1995) and the gene replacement approach described here. A comparison of the relative yields of antimicrobial activity generated by these two systems (in cell-free supernatants) indicated that the latter production host always gave higher values for each variant (determined in plate diffusion bioassays). In the case of the wild-type nis $A$ gene, plasmid-complementation in the host strain FI7332 gave rise to approximately half the yield of nisin found with the parent strain FI5876. The difference between the levels of production was surprisingly more pronounced for the nisin variants. The gene replacement approach increased the Dha5A nisin A yield approximately fourfold and for Dha33A nisin A the yield was over tenfold higher. The increased efficiency of production of the double mutant Dha5A/Dha33A nisin $A$ was particularly striking. When the gene that specified this variant nisin was plasmid-encoded and used to complement the host strain's nis $A$-deficiency, antimicrobial activity was only detected in the more sensitive colony overlay assay (Dodd et al., 1995). However, when the gene was incorporated into the chromosome the level of antimicrobial activity was equivalent to that of nisin A. The reason for this is not clear; however, these obser- 
vations underline the limitations of the FI7332 expression system that employs plasmid-complementation for production of nisin (Dodd et al., 1992, 1995). The insertional inactivation of nis $A$ suffered by this strain is thought to have resulted in the introduction of a constitutive promoter for the nisin operon (Dodd et al., 1992). In contrast, the equivalent $\mathrm{Nis}^{+}$FI7990-derivatives, generated by gene replacement, will still be subject to the same autoinduction mechanism as the wild-type strain (Kuipers et al., 1995).

Theoretically many different types of alterations could be introduced into the nisin molecule using the protein engineering approach. The system described here may, in practice, be limited to the production of only those variants that are not antagonistic towards the production strain and respond to the hosts' maturation and immunity machinery. An additional consideration is the requirement, by this expression system, for autoinduction by the mature nisin molecule in the external medium. It has been demonstrated that the antimicrobial activity of nisin variants and their ability to induce expression of the nisin operon are not directly related (Kuipers et al., 1995). Consistent with this is the discovery that $\mathrm{K} 12 \mathrm{~L}$ nisin A, which retains the specific activity of wild-type nisin, and I30W nisin A, which is slightly less active (Table 2), do not function as effectively as inducing agents (H. M. Dodd, N. Horn \& C. J. Giffard, unpublished data). The production levels of these strains were found to be much lower than the parent strain. However, this could be remedied by carrying out the fermentations in the presence of inducing levels of nisin. These strains also displayed lower levels of nisin immunity (Table 1) consistent with the proposed genetic link between biosynthesis and immunity (Kuipers et al., 1993; Dodd et al., 1992). Similar attempts to induce detectable levels of activity by strain FI8290, encoding nis $A / \Delta \mathrm{M} 21$, were not successful. This may imply that the antimicrobial activity of this nisin variant has been lost as a result of a deletion of the methionine residue at position 21 . However, an investigation of the gene expression levels in this strain is needed to support this interpretation.

In the search for altered nisins displaying more efficient or beneficial properties under different conditions, the approach described here increases the likelihood of achieving antimicrobial activity and genetic stability in any engineered strains. In addition, the development of a nis $A$ cassette vector extends the possible ways in which gene replacement can be used to adapt and exploit the existing nisin biosynthesis mechanism.

\section{REFERENCES}

Biswas, I., Gruss, A., Ehrlich, S. D. \& Maguin, E. (1993). Highefficiency gene inactivation and replacement system for grampositive bacteria. J Bacteriol 175, 3628-3635.

Casadaban, M. J. \& Cohen, S. N. (1980). Analysis of gene control signals by DNA fusion and cloning in Escherichia coli. J Mol Biol 138, 179-207.

Chambers, S. P., Prior, S. E., Barstow, D. A. \& Minton, N. P. (1988). The pMTL nic cloning vectors. I. Improved pUC polylinker regions to facilitate the use of sonicated DNA for nucleotide sequencing. Gene 68, 139-149.

Chan, W. C., Bycroft, B. W., Lian, L.-Y. \& Roberts, G. C. K. (1989). Isolation and characterization of two degradation products derived from the peptide antibiotic nisin. FEBS Lett 252, 29-36.

Chopin, M.-C., Chopin, A., Rouault, A. \& Galleron, N. (1989). Insertion and amplification of foreign genes in the Lactococcus lactis subsp. lactis chromosome. Appl Environ Microbiol 55, 1769-1774.

Dodd, H. M. \& Gasson, M. J. (1994). Bacteriocins of lactic acid bacteria. In Genetics and Biotechnology of Lactic Acid Bacteria, pp. 211-251. Edited by M. J. Gasson \& W. M. de Vos. Glasgow: Blackie Academic \& Professional

Dodd, H. M., Horn, N. \& Gasson, M. J. (1990). Analysis of the genetic determinant for the peptide antibiotic nisin. J Gen Microbiol 136, 555-566.

Dodd, H. M., Horn, N., Zhang, H. \& Gasson, M. J. (1992). A lactococcal expression system for engineered nisins. Appl Environ Microbiol 58, 3683-3693.

Dodd, H. M., Horn, N. \& Gasson, M. J. (1995). A cassette vector for protein engineering the lantibiotic nisin. Gene 162, 163-164.

Engelke, G., Gutowski-Eckel, Z., Kiesau, P., Siegers, K., Hammelmann, M. \& Entian, K.-D. (1994). Regulation of nisin biosynthesis and immunity in Lactococcus lactis 6F3. Appl Environ Microbiol 60, 814-825.

Gasson, M. J. (1983). Plasmid components of Streptococcus lactis NCDO 712 and other lactic streptococci after protoplast-induced curing. $J$ Bacteriol 154, 1-9.

Holo, H. \& Nes, I. F. (1989). High-frequency transformation by electroporation of Lactococcus lactis subsp. cremoris grown with glycine in osmotically stabilized media. Appl Environ Microbiol 55, 3119-3123.

Horn, N., Swindell, S. R., Dodd, H. M. \& Gasson, M. J. (1991). Nisin biosynthesis genes are encoded by a novel conjugative transposon. Mol \& Gen Genet 228, 129-135.

Klein, C. \& Entian, K.-D. (1994). Genes involved in self-protection against the lantibiotic subtilin produced by Bacillus subtilis ATCC 6633. Appl Environ Microbiol 60, 2793-2801.

Klein, C., Kaletta, C., Schnell, N. \& Entian, K.-D. (1992). Analysis of genes involved in biosynthesis of the lantibiotic subtilin. Appl Environ Microbiol 58, 132-142.

Klein, C., Kaletta, C. \& Entian, K.-D. (1993). Biosynthesis of the lantibiotic subtilin is regulated by a histidine kinase/response regulator system. Appl Environ Microbiol 59, 296-303.

Kuipers, O. P., Rollema, H. S., Yap, W. M. G. J., Boot, H. J., Siezen, R. J. \& de Vos, W. M. (1992). Engineering dehydrated amino acid residues in the antimicrobial peptide nisin. I Biol Chem 267, 24340-24346

Kuipers, O. P., Beerthuyzen, M. M., Siezen, R. J. \& de Vos, W. M. (1993). Characterization of the nisin gene cluster nis ABTCIPR of Lactococcus lactis. Eur J Biochem 216, 281-291.

Kuipers, O. P., Beerthuyzen, M. M., De Ruyter, P. G. G. A., Luesink, E. J. \& de Vos, W. M. (1995). Autoregulation of nisin biosynthesis in Lactococcus lactis by signal transduction. $J$ Biol Chem (in press).

Leenhouts, K. J., Kok, J. \& Venema, G. (1989). Campbell-like integration of heterologous plasmid DNA into the chromosome of Lactococcus lactis subsp. lactis. Appl Environ Microbiol 55, 394- 400.

Leenhouts, K. J., Kok, J. \& Venema, G. (1990). Stability of integrated plasmids in the chromosome of Lactococcus lactis. Appl Environ Microbiol 56, 2726-2735. 
Lennox, E. S. (1955). Transduction of linked genetic characters of the host bacteriophage P1. Virology 1, 190-206.

Liu, W. \& Hansen, J. N. (1992). Enhancement of the chemical and antimicrobial properties of subtilin by site-directed mutagenesis. $J$ Biol Chem 267, 25078-25085.

Liu, W. \& Hansen, J. N. (1993). The antimicrobial effect of a structural variant of subtilin against outgrowing Bacillus cereus $\mathrm{T}$ spores and vegetative cells occurs by different mechanisms. Appl Environ Microbiol 59, 648-651.

Mulders, J. W. M., Boerrigter, I. J., Rollema, H. S., Siezen, R. J. \& de Vos, W. M. (1991). Identification and characterization of the lantibiotic nisin Z, a natural nisin variant. Eur J Biochem 201, 581-584.

Rauch, P. J. G., Kuipers, O. P., Siezen, R. J. \& de Vos, W. M. (1994). Genetics and protein engineering of nisin. In Bacteriocins of Lactic Acid Bacteria, pp. 223-250. Edited by L. De Vuyst \& E. J. Vandamme. Glasgow: Blackie Academic \& Professional.

Rollema, H. S., Kuipers, O. P., Both, P., de Vos, W. M. \& Siezen, R.
J. (1995). Improvement of solubility and stability of the antimicrobial peptide nisin by protein engineering. Appl Environ Microbiol 61, 2873-2878.

Siegers, K. \& Entian, K.-D. (1995). Genes involved in immunity to the lantibiotic nisin produced by Lactococcus lactis 6F3. Appl Environ Microbiol 61, 1082-1089.

Terzaghi, B. E. \& Sandine, W. E. (1975). Improved medium for lactic streptococci and their bacteriophages. Appl Microbiol 29, 807-813.

de Vos, W. M., Jung, G. \& Sahl, H.-G. (1991). Definitions and nomenclature of lantibiotics. In Nisin and Novel Lantibiotics, pp. 457-463. Edited by G. Jung \& H.-G. Sahl. Leiden: ESCOM.

de Vos, W. M., Beerthuyzen, M. M., De Ruyter, P., Luesink, E. \& Kuipers, O. P. (1994). Control of nisin gene expression system. Proceedings of the 2 nd International Workshop on Lantibiotics, Papendal, The Netherlands.

Received 25 August 1995; accepted 13 September 1995. 